\title{
Chiral Polyurea with L-Lysinyl Residue Aimed for Optical Resolution
}

\author{
Makoto Hatanaka, Yuki Nishioka and Masakazu Yoshikawa*
}

\author{
Department of Biomolecular Engineering, Kyoto Institute of Technology, Matsugasaki, Kyoto 606-8585, \\ Japan
}

\begin{abstract}
Novel polyurea was synthesized from lysinyl residue, L-lysine-4-nitroanilide (L-Lys-4-NA) and 1,4-phenylene diisocyanate (1,4-PDI). The polyurea thus prepared gave durable self-standing membranes. The polyurea was converted into molecular recognition materials by using Z-D-Glu or Z-L-Glu as a print molecule. The Z-D-Glu molecularly imprinted membrane adsorbed the D-isomer of Glu in preference to the corresponding L-isomer and vice versa. Even though the polyurea consisted of L-lysinyl residue, both Z-D-Glu and Z-L-Glu worked as print molecules to construct molecular (chiral) recognition sites in the membrane. Those two types of molecularly imprinted membrane show chiral separation abilities, adopting a concentration gradient or an applied potential difference as a driving force for membrane transport.
\end{abstract}

Keywords: Chiral Separation, Membrane, Molecular Imprinting, Optical Resolution, Polyurea.

\section{INTRODUCTION}

In these days, the attentions of membranologists have been mostly focused on water treatment and reduction of carbon dioxide emission. Those are problems the globe has faced and have to be immediately solved. Furthermore, membrane separation is expected to contribute to solve the critical global issues we have faced; (1) environmental problems, such as water pollution by volatile organic compounds (VOCs), endcrine disruptors etc., air pollution, and so forth, (2) energy/resource problems, such as water resources, fuel cell, concentration difference power generation, utilization of biomass, etc., (3) health problems, such as artificial organs, production of pharmaceuticals, production and separation of optically pure drugs, and so forth. As enumerated above, membranes are expected to contribute to the globe as "Green Membranes". Since membrane separation can be operated continuously under mild conditions and is perceived to be economically and ecologically competitive to other separation methods. Membranes are regarded as a promising separation media supporting safe, secure, and sustainable society.

Among problems, which can be solved by using membranes, separation of optically pure compounds from their racemic mixtures is not an urgent problem to be solved. However, it is an important subject to prepare for health problems, which will be soon emerged in the near future. As can be seen in various

\footnotetext{
*Address correspondence to this author at the Department of Biomolecular Engineering, Kyoto Institute of Technology, Matsugasaki, Kyoto 606-8585, Japan; Tel: +81-75-724-7816; Fax: +81-75-724-7800;

E-mail: masahiro@kit.ac.jp
}

review papers [1-5], materials for membranes or stationary phases, which show optical resolution ability, are requisite to contain chiral environment or chiral selector (molecular recognition site) in them. To this end, the authors' research group has been studied optical resolution with membranes, such as polymeric membranes [6-8] and nanofiber membranes [9-12] with molecular recognition sites introduced by an alternative molecular imprinting and those with chiral environment or chiral selector in a main chain $[13,14]$ or in a side chain [15-17].

In a link in the chain of studies on optical resolution with chiral polyurea [18-20], the chiral polyurea was prepared from L-lysine-4-nitroanilide (L-Lys-4-NA) as diamine component and 1,4-phenylene diisocyanate (1,4-PDI) as diisocyanate one. Its membrane performance was investigated adopting racemic mixture of glutamic acid (Glu) as a model racemate.

\section{EXPERIMENTAL}

\subsection{Materials}

L-Lys-4-NA dihydrobromide (L-Lys-4-NA/2HBr) was purchased from BACHEM AG and used without further purification. 1,4,-PDI was purified by sublimation under vacuum [21]. N- $\alpha$-Benzyloxycrbonyl-D-glutamic acid (ZD-Glu) and N- $\alpha$-benzyloxycarbonyl-L-glutamic acid (Z-LGlu) were purchased from Watanabe Chemical Ind., Ltd. (Hiroshima, Japan) and used without purification. Methanol, ethanol, 1,1,1,3,3,3-hexafluoro-2-propanol (HFIP), D-glutamic acid (D-GLu), and L-glutamic acid (LGlu) were obtained from commercial sources and used as received. Dimethylacetamide (DMAc), and triethylamine (TEA) were purified by the conventional methods [22]. Water purified with an ultrapure water 
system (Simpli Lab. Millilpore S. A., Molshein, France) was used.

\subsection{Polyaddition}

Requisite amounts of chemicals were placed in a reaction flask fitted with a condenser and a thermometer. The mixture was magnetically stirred at 0 ${ }^{\circ} \mathrm{C}$ for $18 \mathrm{~h}$. The resulting solution was poured into water under rapid stirring, and the precipitate product was washed with water and then with methanol and dried in vacuo.

\subsection{Characterization of the Polyurea}

The viscosity number was determined with an Ubbelohde viscometer at a concentration of $5.0 \times 10^{-3} \mathrm{~g}$ $\mathrm{cm}^{-3}$ in DMAc/LiCl (5 wt.\%) at $25^{\circ} \mathrm{C}$.

The IR spectrum was recorded by using a PerkinElmer Spectrum GX; 64 scans at a resolution of $4 \mathrm{~cm}^{-1}$ were collected with a membrane, which was prepared from HFIP solution.

The ${ }^{1} \mathrm{H}$ NMR spectrum was recorded in DMF- $\mathrm{d}_{7}$ using a BRUKER AV-300 with residual partially protonated solvent of DMF- $d_{7}$ as an internal standard $(\delta=2.91[23])$.

The thermal stability of the polyurea was evaluated on a Hi-Res Modulated TGA 2950 (TA Instruments, Inc.) under nitrogen at heating rate of $10^{\circ} \mathrm{C} \mathrm{min}^{-1}$.

Dynamic mechanical thermal analysis (DMTA) measurement was carried out with a dynamic mechanical analyzer, RSA III (TA Instruments, Inc.) in tension mode. The experiment was performed at a frequency of $1 \mathrm{~Hz}$ and a heating rate of $1.0^{\circ} \mathrm{C} \mathrm{min}{ }^{-1}$ from 30 to $200^{\circ} \mathrm{C}$. The dimension of sample was 20.26 $\times 6.23 \times 0.118 \mathrm{~mm}^{3}$.

The specific rotations were obtained with Horiba SEPA-200 polarimeter at $589 \mathrm{~nm}$ at ambient temperature in DMF.

\subsection{Membrane Preparation}

The control membrane was prepared as follows: 60 $\mathrm{mg}$ of polyurea was dissolved in $1.20 \mathrm{~cm}^{3}$ of DMAc. The polymer solution thus prepared was poured into a flat laboratory dish with $6.0 \mathrm{~cm}$ diameter, and the solvent was allowed to evaporate at $50{ }^{\circ} \mathrm{C}$ for 2 days. The thickness of the control membrane thus obtained was around $25.8 \mu \mathrm{m}$.
Molecularly imprinted polyurea membranes were also prepared. In the preparation of molecularly imprinted membranes, it was requisite to know the amount of the lysinyl residue in the polyurea, which was adopted as a candidate material for chiral separation membrane. To this end, it was necessary to know the amount of lysinyl residue in the polyurea to determine the molecular imprinting ratio, which was the mole ratio of the amount of print molecule to that of lysinyl residue in polyurea. Since the lysinyl residue in the polyurea was expected to dominantly show a role to construct chiral (molecular) recognition sites. In the present study, the polyurea was prepared by stepgrowth addition reaction, in other words, no by-product was emerged during polymerization. This simplified the polymerization process, even though biuret group was also formed in addition to urea linkage during the polymerization reaction [24, 25]. The amount of lysinyl residue in the candidate polyurea (Exp. No. 7 in Table 1) was determined to be $2.18 \times 10^{-3}$ mol Lys per $\mathrm{g}$ polyurea, assuming that the polyaddition reaction was quantitatively proceeded, in other words, the composition of the obtained polyurea was exactly equal to the monomer composition. About $60.0 \mathrm{mg}$ of $(1.31 \mathrm{x}$ $10^{-4} \mathrm{~mol}$ of lysinyl residue) of polyurea (Exp. No. 7 in Table 1) and $18.4 \mathrm{mg}\left(6.54 \times 10^{-5} \mathrm{~mol}\right)$ of a print molecule (Z-D-Glu or Z-L-Glu) were dissolved in 1.20 $\mathrm{cm}^{3}$ of DMAc. The imprinting ratio, the mole ratio of the amount of print molecule to that of lysinyl residue in polyurea, was fixed to be 0.50 . The solution was poured into a flat laboratory dish with $6.0 \mathrm{~cm}$ diameter and dried at $50{ }^{\circ} \mathrm{C}$ for 2 days to evaporate the solvent. After drying, the print molecule was extracted from the resultant membrane by a large amount of 50 vol.-\% aqueous ethanol until the print molecule was hardly detected in aqueous ethanol solution by UV analysis. In the present study, most of adopted print molecule was leached from the membrane. Thickness of the membrane thus obtained was around $28.4 \mu \mathrm{m}$ for the Z-D-Glu molecularly imprinted membrane and $28.2 \mu \mathrm{m}$ for the Z-L-Glu one, respectively.

\subsection{Adsorption Selectivity}

Membranes were immersed in racemic mixture of Glu solution, similar to the mixture studied in enantioselective transport and enantioselective electrodialysis, that is, aqueous solution of racemic Glu (each concentration of Glu, $1.0 \times 10^{-3} \mathrm{~mol} \mathrm{dm}^{-3}$ ), and the membrane was allowed to be equilibrated at $40^{\circ} \mathrm{C}$. A 0.02 wt.-\% of sodium azide was added as a fungicide. In the present study, the amount of racemic Glu adsorbed in the membrane was too low to be 
Table 1: Polyaddition Reaction of L-Lys-4-NA/2HBr and 1,4-PDI

\begin{tabular}{|c|c|c|c|c|c|c|c|}
\hline \multirow{2}{*}{$\begin{array}{l}\text { Exp. } \\
\text { No. }\end{array}$} & [L-Lys-4-NA]/[1,4-PDI] & L-Lys-pNA $2 \mathrm{HBr}$ & 1,4-PDI & DMAC & TEA & Yield & $\eta ; C^{b}$ \\
\hline & & $\begin{array}{c}\mathrm{g} \\
\left(\mathrm{mol} \mathrm{dm}{ }^{-3}\right)\end{array}$ & $\begin{array}{c}\mathrm{g} \\
\left(\mathrm{mol} \mathrm{dm}^{-3}\right)\end{array}$ & $\mathrm{cm}^{3}$ & $\mathrm{~cm}^{3}$ & $\begin{array}{l}g \\
(\%)\end{array}$ & $\mathrm{g}^{-1} \mathrm{~cm}^{3}$ \\
\hline \multirow{2}{*}{1} & \multirow{2}{*}{1.00} & 0.6422 & 0.2402 & \multirow{2}{*}{9.55} & \multirow{2}{*}{0.45} & 0.5412 & \multirow{2}{*}{53.95} \\
\hline & & $\left(1.50 \times 10^{-1}\right)$ & $\left(1.50 \times 10^{-1}\right)$ & & & (84.61) & \\
\hline \multirow{2}{*}{2} & \multirow{2}{*}{1.00} & 0.6423 & 0.2409 & \multirow{2}{*}{7.05} & \multirow{2}{*}{0.45} & 0.4828 & \multirow{2}{*}{28.53} \\
\hline & & $\left(2.00 \times 10^{-1}\right)$ & $\left(2.00 \times 10^{-1}\right)$ & & & (75.47) & \\
\hline \multirow{2}{*}{3} & \multirow{2}{*}{1.00} & 0.6423 & 0.2403 & \multirow{2}{*}{5.55} & \multirow{2}{*}{0.45} & 0.5467 & \multirow{2}{*}{49.77} \\
\hline & & $\left(2.50 \times 10^{-1}\right)$ & $\left(2.50 \times 10^{-1}\right)$ & & & (85.47) & \\
\hline \multirow{2}{*}{4} & \multirow{2}{*}{1.00} & 0.6421 & 0.2402 & \multirow{2}{*}{4.55} & \multirow{2}{*}{0.45} & 0.5451 & \multirow{2}{*}{65.19} \\
\hline & & $\left(3.00 \times 10^{-1}\right)$ & $\left(3.00 \times 10^{-1}\right)$ & & & $(85.22)$ & \\
\hline \multirow{2}{*}{5} & \multirow{2}{*}{0.83} & 0.5352 & 0.2403 & \multirow{2}{*}{9.3} & \multirow{2}{*}{0.7} & 0.5458 & \multirow{2}{*}{150.8} \\
\hline & & $\left(1.25 \times 10^{-1}\right)$ & $\left(1.50 \times 10^{-1}\right)$ & & & (95.25) & \\
\hline \multirow{2}{*}{6} & \multirow{2}{*}{0.83} & 0.5352 & 0.2401 & 68 & 07 & 0.5460 & 0 \\
\hline & & $\left(1.67 \times 10^{-1}\right)$ & $\left(2.00 \times 10^{-1}\right)$ & 0.0 & 0.1 & (95.21) & 200.0 \\
\hline 7 & $08 ?$ & 0.5353 & 0.2401 & $5 ?$ & 07 & 0.5262 & 006 \\
\hline 1 & 0.00 & $\left(2.08 \times 10^{-1}\right)$ & $\left(2.50 \times 10^{-1}\right)$ & 0.0 & 0.1 & $(91.83)$ & 200.4 \\
\hline 8 & 083 & 0.5351 & 0.2402 & 165 & 035 & 0.5427 & 1865 \\
\hline 0 & 0.03 & $\left(2.50 \times 10^{-1}\right)$ & $\left(3.00 \times 10^{-1}\right)$ & 4.05 & 0.05 & $(94.70)$ & 100.5 \\
\hline 0 & 067 & 0.4281 & 0.2401 & 94 & 06 & 0.4848 & 1627 \\
\hline 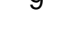 & 0.07 & $\left(1.00 \times 10^{-1}\right)$ & $\left(1.50 \times 10^{-1}\right)$ & 9.4 & 0.0 & (95.72) & 102.1 \\
\hline 10 & 067 & 0.4282 & 0.2402 & 69 & 06 & 0.4899 & 2025 \\
\hline 10 & 0.07 & $\left(1.33 \times 10^{-1}\right)$ & $\left(2.00 \times 10^{-1}\right)$ & 0.5 & 0.0 & (96.73) & $<0<.5$ \\
\hline 11 & 067 & 0.4281 & 0.2402 & 54 & 06 & 0.4853 & 1880 \\
\hline 11 & 0.67 & $\left(1.67 \times 10^{-1}\right)$ & $\left(2.50 \times 10^{-1}\right)$ & 5.4 & 0.6 & (95.82) & 188.9 \\
\hline 12 & 067 & 0.4282 & 0.2401 & 47 & 03 & 0.4715 & 1675 \\
\hline 16 & $0.0 r$ & $\left(2.00 \times 10^{-1}\right)$ & $\left(3.00 \times 10^{-1}\right)$ & 4.1 & 0.0 & $(93.07)$ & 107.0 \\
\hline 12 & 050 & 0.3211 & 0.2402 & 060 & 010 & 0.4016 & 1277 \\
\hline 10 & 0.50 & $\left(7.50 \times 10^{-2}\right)$ & $\left(1.50 \times 10^{-1}\right)$ & 3.00 & 0.40 & $(91.30)$ & 101.1 \\
\hline 14 & 050 & 0.3211 & 0.2402 & 710 & 010 & 0.4037 & 1117 \\
\hline 14 & 0.50 & $\left(1.00 \times 10^{-1}\right)$ & $\left(2.00 \times 10^{-1}\right)$ & 1.10 & 0.40 & (91.77) & 141.8 \\
\hline 15 & 050 & 0.3211 & 0.2403 & 560 & 010 & 0.4209 & 1508 \\
\hline 10 & 0.50 & $\left(1.25 \times 10^{-1}\right)$ & $\left(2.50 \times 10^{-1}\right)$ & 0.00 & 0.40 & (95.67) & 159.0 \\
\hline 16 & 050 & 0.3211 & 0.2403 & 475 & 025 & 0.3984 & 1710 \\
\hline 10 & 0.50 & $\left(1.50 \times 10^{-1}\right)$ & $\left(3.00 \times 10^{-1}\right)$ & 4.15 & 0.25 & $(90.56)$ & 171.0 \\
\hline
\end{tabular}

${ }^{\mathrm{a}}$ Polymerization temp., $0{ }^{\circ} \mathrm{C}$; polyrmerization time, $18 \mathrm{~h}$.

${ }^{b}$ Measured at a concentration of $5.0 \times 10^{-3} \mathrm{~g} \mathrm{~cm}^{-3}$ in DMAc/LiCl (5 wt.\%) at $25^{\circ} \mathrm{C}$.

determined precisely by the aliquots of the solution after equilibrium had been reached. From this, that was determined by desorption method; the membrane, which had reached equilibrium with racemic Glu solution, was taken out from the immersing solution, blotted free solution adhering on the surface, and then transferred to a 0.02 wt.- $\% \mathrm{NaN}_{3}$ aqueous solution to desorb the racemic Glu from the membrane. Aliquots of the solution of adsorption after equilibrium had been reached and that for desorption were used for quantitative estimation by liquid chromatography (LC) [Jasco PU-2080, equipped with a UV detector (Jasco UV-2075)], using a CHIRALPAK MA(+) column [50 $\mathrm{x}$ $4.6 \mathrm{~mm}$ (id)] (Daicel Chemical Ind.) and aqueous copper sulfate solution as an eluent.

The amount of Glu in the desorption gave the amount of Glu adsorbed by the membrane. The adsorption selectivity $S_{A(i j)}$ is defined as:

$S_{\mathrm{A}(\mathrm{i} j \mathrm{j})}=((\mathrm{i}-\mathrm{Glu}) /(\mathrm{j}-\mathrm{Glu})) /([\mathrm{i}-\mathrm{Glu}] /[\mathrm{j}-\mathrm{Glu}])$ 
where (i-Glu) and [i-Glu] are the amount of Glu adsorbed in the membrane and the concentration in the solution after equilibrium had been reached. Hereafter, subscripts of $D$ and $L$ mean the $D$ - and L-isomer, respectively.

\subsection{Enantioselective Membrane Transport}

A membrane with area of $3.0 \mathrm{~cm}^{2}$ was fixed tightly with Parafilm between two chambers of a permeation cell. The volume of each chamber was $40.0 \mathrm{~cm}^{3}$. An aqueous solution of racemic Glu was placed in the lefthand chamber (L-side) and an aqueous solution in the right-hand chamber (R-side). Each concentration of racemic Glu was fixed to be $1.0 \times 10^{-3} \mathrm{~mol} \mathrm{dm}^{-3}$. In both chambers, 0.02 wt. $\%$ of sodium azide was added as a fungicide. All experiments were carried out at $40{ }^{\circ} \mathrm{C}$ with stirring. An aliquot was drawn from the permeate side at each sampling time. The amounts of D- and Lisomers transported by the membrane were determined by LC as described above.

The flux, $J\left(\mathrm{~mol} \mathrm{~cm}^{-2} \mathrm{~h}^{-1}\right)$, is defined as:

$J=Q / A t$

where $Q(\mathrm{~mol})$ is the amount of transported Glu, $A$ $\left(\mathrm{cm}^{2}\right)$ the effective membrane area, and $t(\mathrm{~h})$ is the time.

The permselectivity $\alpha_{i j}$ is defined as the flux ratio $J_{\mathrm{i}} / J_{\mathrm{j}}$ divided by the concentration ratio [i-Glu] / [j-Glu]:

$\alpha_{\mathrm{ijj}}=\left(J_{\mathrm{i}} / J_{\mathrm{j}}\right) /([\mathrm{i}-\mathrm{Glu}] /[\mathrm{j}-\mathrm{Glu}])$

\subsection{Enantioselective Electrodialysis}

An aqueous solution of racemic Glu was placed in each chamber of the permeation cell. Each concentration of racemic Glu was fixed to be $1.0 \times 10^{-3}$ $\mathrm{mol} \mathrm{dm^{-3 }}$. The electrodialysis was carried out with a prescribed applied potential difference between platinum electrodes $\left(1.0 \mathrm{~cm}^{2}\right.$; distance between the electrodes, $7.0 \mathrm{~cm}$ ) at $40{ }^{\circ} \mathrm{C}$ with stirring. An aliquot was drawn from the transport side (R-side) at each sampling time. The amounts of D-Glu and L-Glu transported through the membrane were determined by LC as described above.

\section{RESULTS AND DISCUSSION}

\subsection{Syntheses of Polyurea}

A novel chiral polyurea was prepared from L-Lys-4NA with asymmetric carbon and 1,4,-PDI by polyaddition reaction. The polymerization scheme is shown in Figure 1. In IR spectrum of newly prepared polyurea, characteristic absorption bands at $1656 \mathrm{~cm}^{-1}$ assigned to $\mathrm{C}=\mathrm{O}$ stretching band of urea and amide I band, that at $1552 \mathrm{~cm}^{-1}$ assigned to asymmetric vibration of $-\mathrm{NO}_{2}$, and that at $1341 \mathrm{~cm}^{-1}$ assigned to asymmetric stretching vibration of $-\mathrm{NO}_{2}$ were detected. The ${ }^{1} \mathrm{H}$ NMR spectrum of polyurea (Exp. No. 7 in Table $\mathbf{1}$ ) is shown in Figure 2.

The IR and ${ }^{1} \mathrm{H}$ NMR spectra revealed that the expected polyurea was obtained from L-Lys-4-NA and 1,4-PDI. However, stereoregularity of the polyurea as given in Figure $\mathbf{1}$ and the composition of urea and biuret linkage $[23,24]$ in the present polyurea were hardly determined.

Optimization of polyaddition reaction is indispensable to obtain durable membranes from the present polyurea. To this end, first, effect of monomer concentration on polyaddition reaction was studied
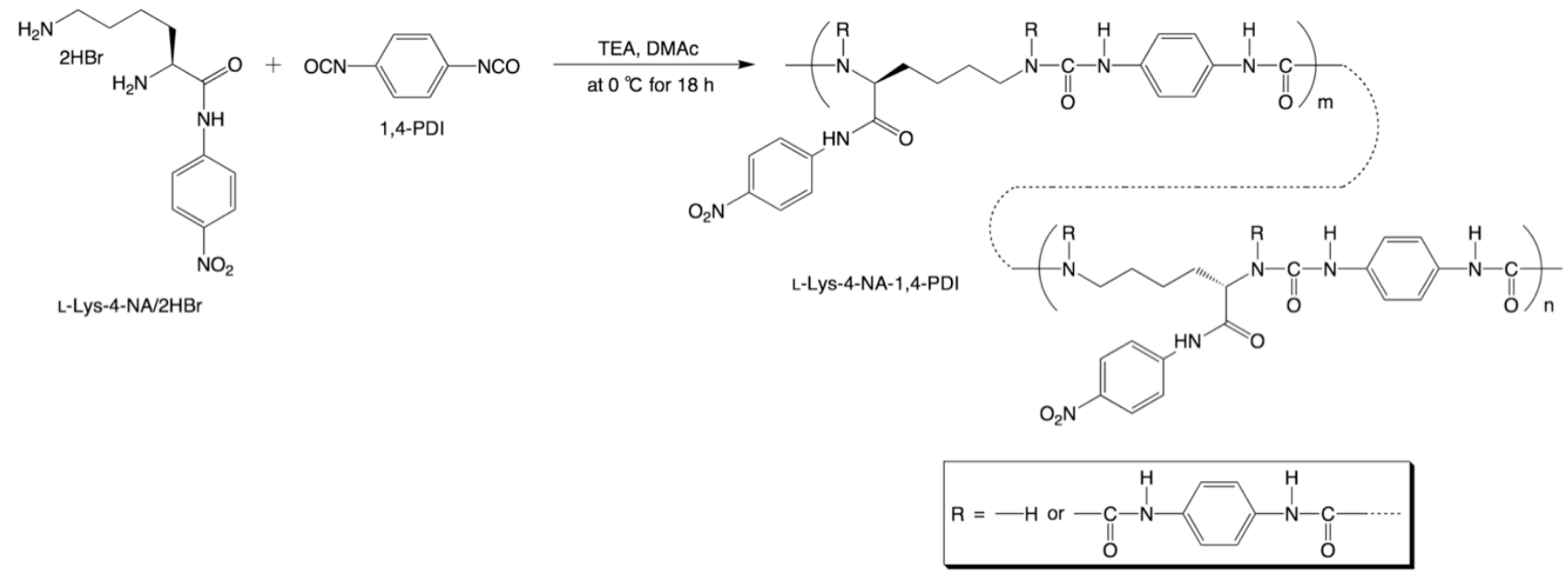

Figure 1: Polymerization scheme of chiral polyurea (L-Lys-4-NA-1,4-PDI). 

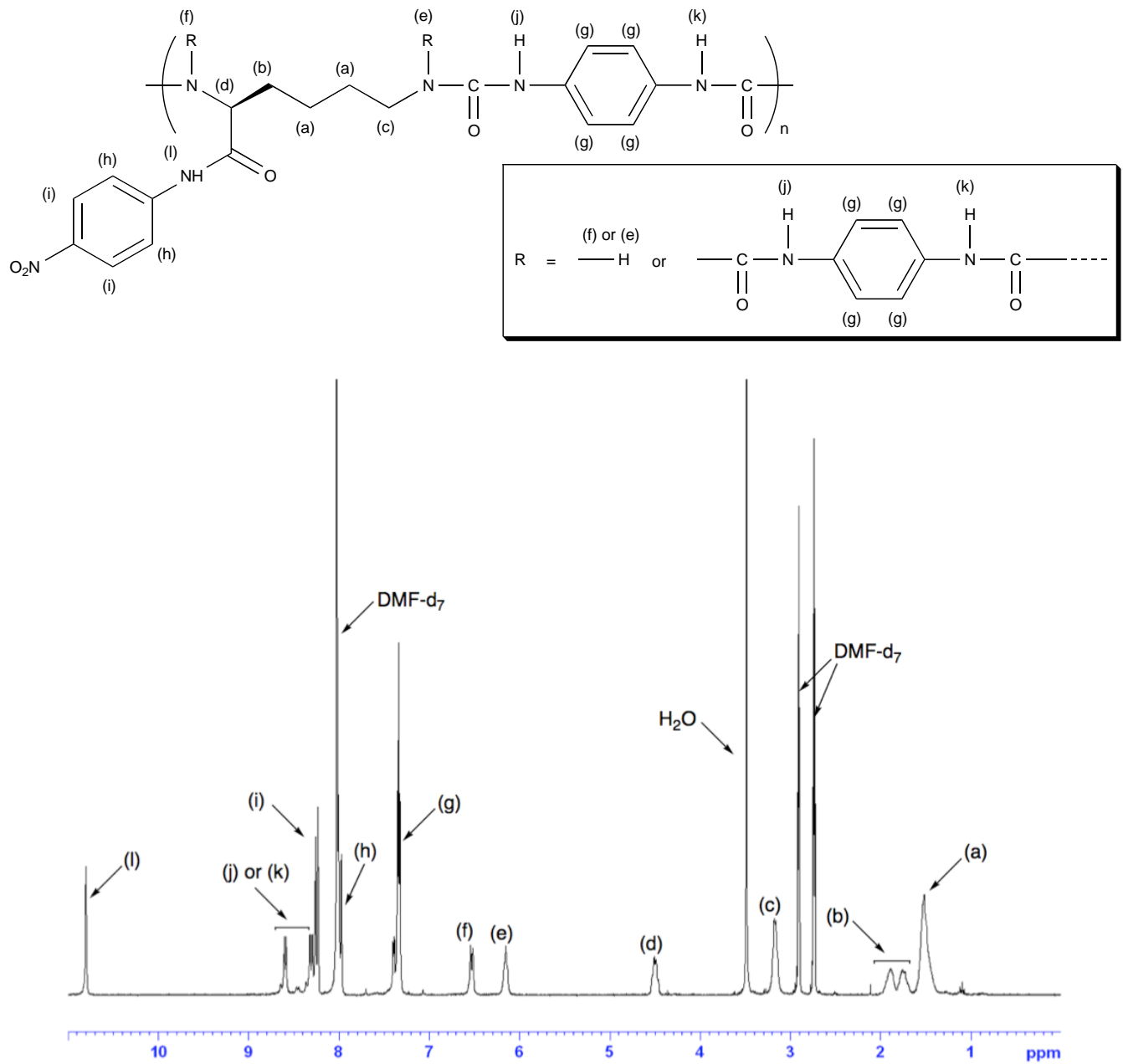

Figure 2: ${ }^{1} \mathrm{H}$ NMR spectrum of L-Lys-4-NA-1,4-PDI (Exp. No. 7 in Table 1).

adopting equimolar amount of each monomer (Exp. No. 1 - 4 in Table 1). The viscosity number, which can be correlated to molecular weight, was adopted as an index to the present study. The molecular weight (viscosity number) of polyurea (Exp. No. $1-4$ in Table 1) was too low to give a durable self-standing membrane. From the reaction conditions that the molar ratio of two types of monomer, [L-Lys-4-NA]/[1,4-PDI], was unity, most linkage formed in the polyurea was though to be a urea unit. The introduction of long side chains is expected to both increase the molecular weight and enhance the entanglement of polymer chains. This would be one of smart ways to obtain durable self-standing membranes from the present chiral polyureas. To this end, the introduction of biuret linkage into the polyurea was attempted.

The polyaddition reaction with the monomer ratio, [L-Lys-4-NA]/[1,4-PDI], of $0.83,0.67$, and 0.50 was studied in addition to that of unity. Those results are also summarized in Table 1 (Exp. No. 5 -16), as well. Those results are visually shown in Figure 3 for convenience. Among those sixteen experiments, the polyurea prepared under the polyaddition reaction of the monomer ratio of 0.83 and the 1,4-PDI concentration of $2.50 \times 10^{-1} \mathrm{~mol} \mathrm{dm}^{-3}$ (Exp. No. 7 in Table 1) gave the highest viscosity number. In the present paper, hereafter, this polyurea was adopted as a candidate material for membrane study.

\subsection{Characterization of Polyurea}

Thermogravimetric analysis of polyurea (Exp. No. 7 in Table 1) was carried out and its thermograph is shown in Figure 4. The degradation temperature of the present polyurea was determined to be $216.5^{\circ} \mathrm{C}$. LLys-4-NA-2,4-TDI, which consisted of the same lysine derivative of L-Lys-4-NA and 2,4-toluene diisocyanate (2,4-TDI), showed the degradation temperature of $231.4{ }^{\circ} \mathrm{C}[20]$, which was around $15^{\circ} \mathrm{C}$ higher than that of the present polyurea. This might be due to the bulkiness of methyl group in 2,4-TDI unit rather than to the rigidness of $1,4-\mathrm{PDI}$ unit $[24,26]$. Contrary to this, the $T_{\mathrm{d}}$ of the present polyurea was aroud $9^{\circ} \mathrm{C}$ higher 


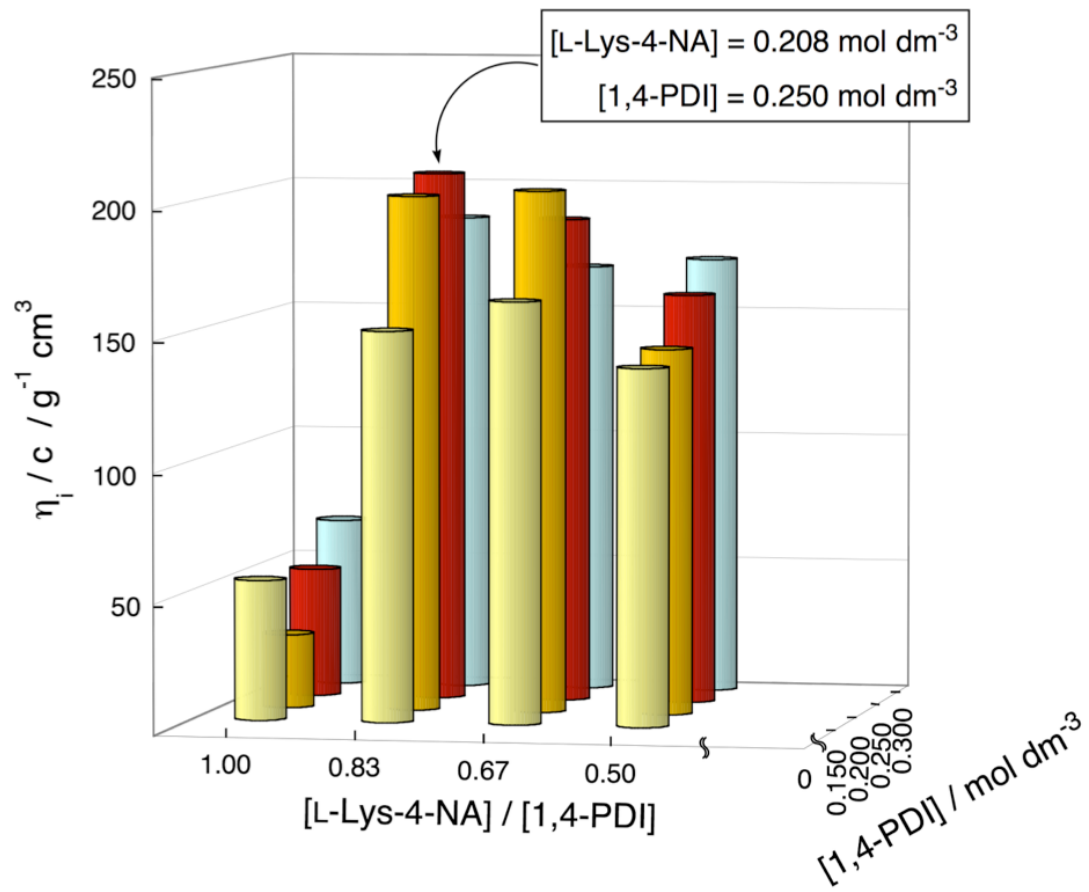

Figure 3: Results of polyaddition reaction of L-Lys-4-NA and 1,4-PDI.

than that of L-Lys-OEt-1,4-PDI $\left(T_{\mathrm{d}}, 207.7^{\circ} \mathrm{C}\right)$, which was prepared from the same diisocyanate monomer, 1,4-PDI, and L-lysine ethyl ester (L-Lys-OEt) [18]. This is thought to be due to the steric hindrance of the bulkiness of a protecting group of 4-nitroanilide in LLys-4-NA unit.

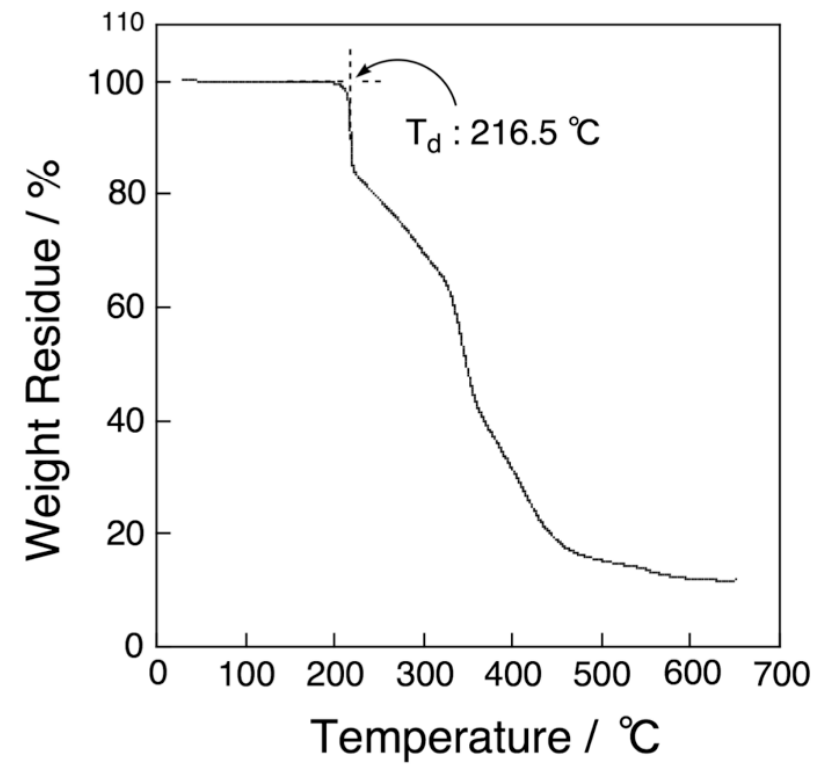

Figure 4: Thermogravimetric analysis curve of L-Lys-4-NA1,4-PDI (Exp. No. 7 in Table 1). (Heating rate, $10^{\circ} \mathrm{C} \mathrm{min}^{-1}$ ).

Figure 5 shows dependences of dynamic storage modulus $E^{\prime}$, dynamic loss modulus $E^{\prime \prime}$, and $\tan \delta$ on temperature for the polyurea (Exp. No. 7 in Tanle 1). The single peak of tan $\delta$, assigned to the glass transition temperature, can be found at $198.1^{\circ} \mathrm{C}$, which was higher than those of L-Lys-4-NA-2,4-TDI $\left(162.9^{\circ} \mathrm{C}\right.$ [20]) and L-Lys-OEt-1,4-PDI (186.1 ${ }^{\circ} \mathrm{C}$ [18]). The 2,4TDI, which was a component of L-Lys-4-NA-2,4-TDI, is more flexible than the 1,4-PDI in the present polyurea and the protecting group of ethoxy moiety in L-Lys-OEt unit is smaller than that of 4-nitroanilide in L-Lys-4-NA unit. Therefore, the present polyurea L-Lys-4-NA-1,4PDI gave higher glass transition temperature than those polyureas.

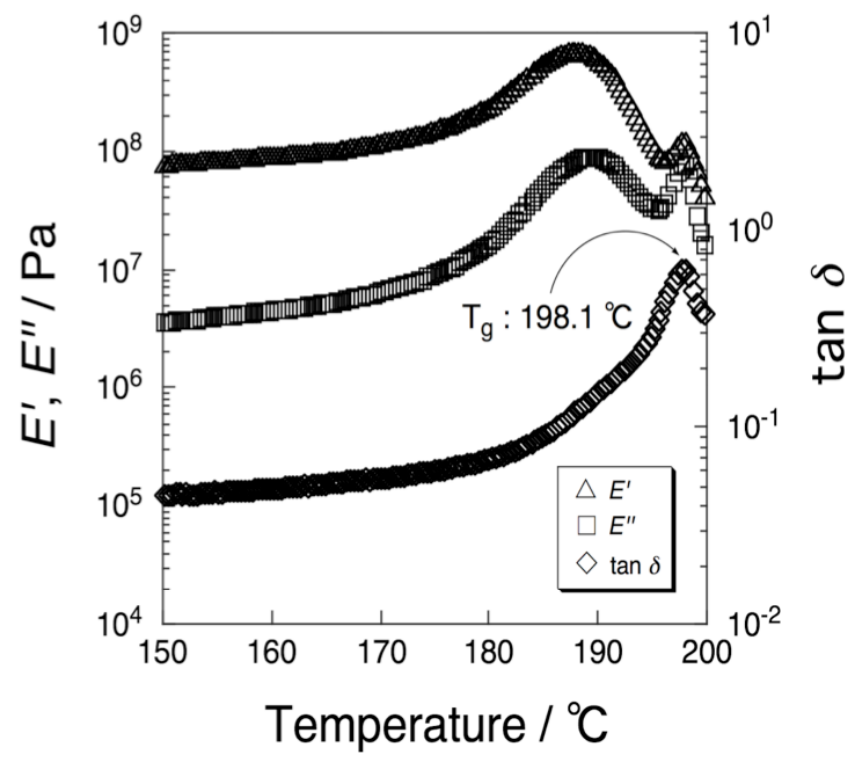

Figure 5: Temperature dependence of $E^{\prime}, E^{\prime \prime}$, and $\tan \delta$ for the chiral polyurea (Exp. No. 7 in Table 1) at a frequency of 1 $\mathrm{Hz}$ and a heating rate of $1.0^{\circ} \mathrm{C} \mathrm{min}^{-1}$. 
The optical rotation, $[\alpha]_{D}$, of the polyurea and the corresponding starting material of L-Lys-4-NA/2HBr are shown in Table 2. The results revealed that optically active polyurea was obtained. From this, the membranes from the present polyurea were expected to express chiral separation ability since there can be found chiral environment in the present polyurea.

Table 2: Specific Rotations of Diamine Monomer and Chiral Polyurea

\begin{tabular}{|c|c|}
\hline \multirow{2}{*}{} & {$[\alpha]_{\mathrm{D}}$} \\
\cline { 2 - 2 } & $\operatorname{deg~cm}^{2} \mathrm{~g}^{-1}$ \\
\hline \hline L-Lys-4-NA/2HBr & a \\
\hline L-Lys-4-NA-1,4-PDI $^{\mathrm{b}}$ & 45.0 \\
\hline
\end{tabular}

${ }^{a}$ in DMF, $\mathrm{C}=5.00 \mathrm{~g} \mathrm{dL}^{-1}, \mathrm{~L}=10 \mathrm{~cm}$.

in DMF/LiCl (5 wt.\%), $c=1.00 \mathrm{~g} \mathrm{dL}^{-1}, \mathrm{~L}=10 \mathrm{~cm}$.

\subsection{Adsorption Selectivity}

Adsorption selectivity of the present polyurea membrane was studied adopting racemic mixture of Glu as model racemates. The results of adsorption selectivity are summarized in Table $\mathbf{3}$. As observed in adsorption studies on other chiral polyurea membranes [18-20], the control polyurea membrane incorporated into the L-isomer of Glu in preference to the corresponding D-isomer. Even though the present control membrane showed adsorption selectivity, the value was not so prominent and determined to be 1.05 . As reported [27-32], molecular imprinting is a facile way to bestow molecular recognition ability on polymeric materials. However, in the present study, conventional molecular imprinting could not be applicable to give molecular recognition ability into the present polyurea, since polymeric materials were already prepared. In such a case, an alternative molecular imprinting is an effective and a suitable method to introduce molecular recognition sites into polymeric materials, which were already polymerized [6-12,33]. Applying an alternative molecular imprinting, the present polyurea will be directly converted into molecular recognition materials (membranes). To this end, molecularly imprinted membranes were prepared from the present polyurea adopting $\mathrm{N}$ - $\alpha$-protected glutamic acid, such as Z-D-Glu or Z-L-Glu, as a print molecule.

The adsorption selectivities for those molecularly imprinted membranes are also shown in Table $\mathbf{3}$ together with that for control non-imprinted membrane. As expected, the membrane imprinted by Z-D-Glu showed opposite adsorption selectivity to the control non-imprinted membrane. In other words, the Z-D-Glu molecularly imprinted membrane preferentially adsorbed D-Glu and the adsorption selectivity toward the D-isomer was determined to be 1.09. Contrary to this, the Z-L-Glu molecularly imprinted membrane showed the adsorption selectivity of 1.10 toward the Lisomer of Glu. In the authors' previous studies, molecularly imprinted membranes from synthetic achiral polymers, such as carboxylated polysulfone [9,34], polyamide [7], and polysulfone with aldehyde group [12], the chiral print molecule and the antipode equally worked as a print molecule; the adsorption selectivity for the membrane imprinted by the D-isomer gave nearly same selectivity expressed by that imprinted by the antipode.

In the case of molecularly imprinted membranes from tetrapeptide derivatives [8], the formation of molecular recognition site was strictly dependent on the absolute configuration of candidate materials. The tetrapeptide derivative consisting of D-amino acid residues was converted into the $\mathrm{D}$-isomer recognition materials by adopting the D-isomer of print molecule and vice versa, and the print molecule, of which absolute configuration was opposite to that of the tetrapeptide derivative, hardly worked as a print molecule. However, in the present study, the polyurea was flexible enough to construct molecular recognition sites toward the D-isomer by adopting a print molecule of $\mathrm{D}$-isomer derivative and vice versa. The flexibility of the present polyurea was advantageous to construct Disomer and L-isomer recognition membrane depending

Table 3: Adsorption Selectivity of Three Types of Membrane Toward Racemic Mixture of $\mathrm{Glu}_{\mathrm{u}} \mathrm{H}_{2} \mathrm{O}$

\begin{tabular}{|c|c|c|c|c|c|c|}
\hline \multirow[t]{2}{*}{ Membrane } & \multicolumn{2}{|c|}{ D-Glu } & \multicolumn{2}{|c|}{ L-Glu } & \multirow[t]{2}{*}{$S_{A(D / L)}$} & \multirow[t]{2}{*}{$S_{A(L / D)}$} \\
\hline & $10^{5}$ (mol / g-mem.) & $\begin{array}{l}10^{2}(\mathrm{~mol} / \mathrm{mol}(\text { Lys- } \\
\text { residue }))\end{array}$ & $10^{5}$ (mol / g-mem.) & $\begin{array}{l}10^{2}(\mathrm{~mol} / \mathrm{mol}(\text { Lys }- \\
\text { residue }))\end{array}$ & & \\
\hline $\begin{array}{l}\text { Z-D-Glu imprinted } \\
\text { mem. }\end{array}$ & 2.05 & 0.94 & 1.89 & 0.86 & 1.09 & 0.92 \\
\hline control mem. & 3.95 & 1.81 & 4.13 & 1.89 & 0.96 & 1.05 \\
\hline $\begin{array}{l}\text { Z-L-Glu imprinted } \\
\text { mem. }\end{array}$ & 2.44 & 1.12 & 2.70 & 1.24 & 0.91 & 1.10 \\
\hline
\end{tabular}


on the selection of print molecules, but disadvantageous to obtain higher substrate specificity in adsorption selectivity.

\subsection{Enantioselective Transport}

From the results of adsorption selectivity, those membranes were expected to show chiral separation ability. To this end, first, enantioselective transport ability of those three types of membrane were studied adopting racemic mixture of Glu as model racemates and concentration gradient as a driving force for membrane transport. Time-transport curves of racemic mixture of Glu through those membranes are shown in Figure 6.

Two types of molecularly imprinted membrane, such as Z-D-Glu (a) and Z-L-GLu (c) molecularly imprinted ones, showed chiral separation ability. However, against expectation from adsorption selectivity, the observed permselectivities were opposite to their adsorption selectivities. Such a discrepancy between adsorption selectivity and permselectivity is often observed in membrane separation, especially, in optical resolution [6,8,35-38]. This discrepancy was rationalized by the retarded membrane transport of the enantiomer, which was preferentially incorporated into the membrane. The diffusion of the enantiomer selectively adsorbed in the membrane was retarded by a relatively high affinity between the enantiomer and the membrane. As a result, the antipode was transported faster than the enantiomer preferentially incorporated into the membrane.

Against expectation from adsorption selectivity, the control non-imprinted membrane hardly showed permselectivity. This might be also explained by the reduction of diffusivity due to a relatively strong interaction between the membrane and the L-isomer of Glu. If the magnitude of the reduction of diffusivity of the L-isomer had been higher than that observed, permselectivity toward antipode would have been expressed as observed $[6,8,12]$.

It is interesting to transport the enantiomer, which was selectively incorporated into the membrane, faster than the antipode. In other words, it is interesting to construct membrane transport system, of which permselectivity reflects its adsorption selectivity. In the next chapter, such an approach will be described.

\subsection{Enantioselective Electrodialysis}

In order to transport the eanantiomer preferentially adsorbed in the membrane faster than the antipode, the applied potential difference was adopted as a driving force for the membrane transport of racemic Glu through the two types of molecularly imprinted membrane. In other words, enantioselective electrodialysis was applied so that the permselectivity would reflect its adsorption selectivity.

Time-transport curves of racemic Glu at the applied potential difference of $6.0 \mathrm{~V}$ are shown in Figure 7. As can be seen in Figure 7, D-Glu, which was preferentially incorporated into the Z-D-Glu imprinted membrane, was selectively transported through it and vice versa.

The membrane performance, such as permselectivity and flux, was expected to be dependent on the applied potential difference as reported previously $[8,15,18]$. To this end, the membrane performance was investigated at an applied potential difference of $3.0 \mathrm{~V}$ and $9.0 \mathrm{~V}$ and results are summarized in Figure 8 together with that of $6.0 \mathrm{~V}$. In
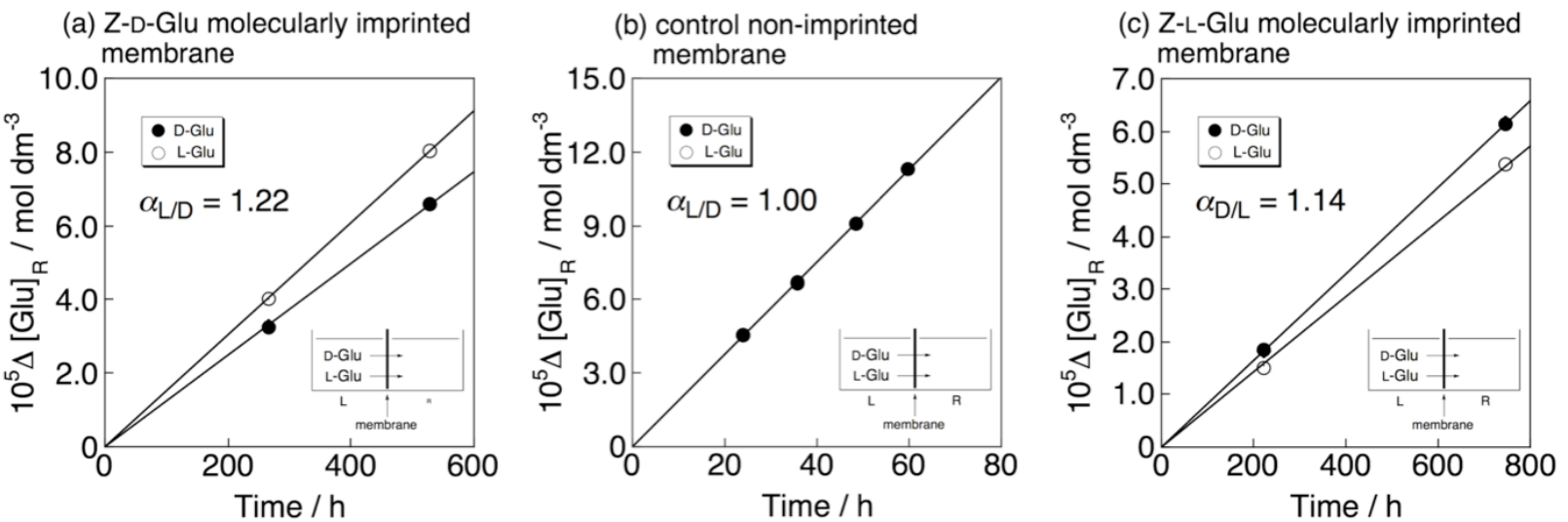

Figure 6: Time-transport curves of racemic mixture of Glu through Z-D-Glu molecularly imprinted (a), control non-imprinted (b), and Z-L-Glu molecularly imprinted (c) membranes at $40{ }^{\circ} \mathrm{C}$ in $\mathrm{H}_{2} \mathrm{O}$ solution adopting a concentration gradient as a driving force for membrane transport. 
(a) Z-D-GLu molecularly imprinted membrane

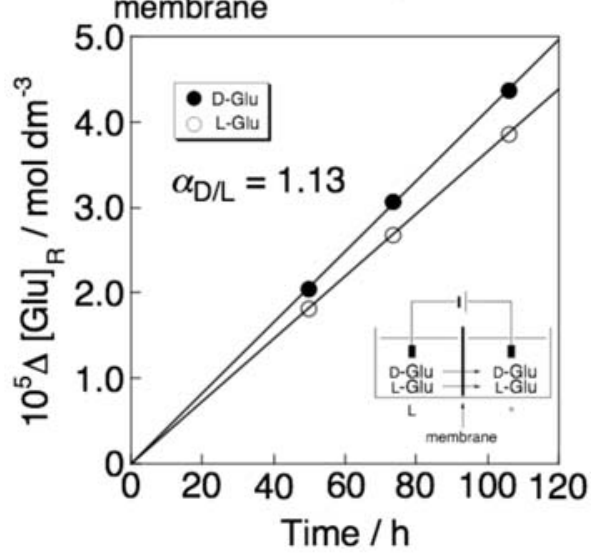

(b) Z-L-GLu molecularly imprinted membrane

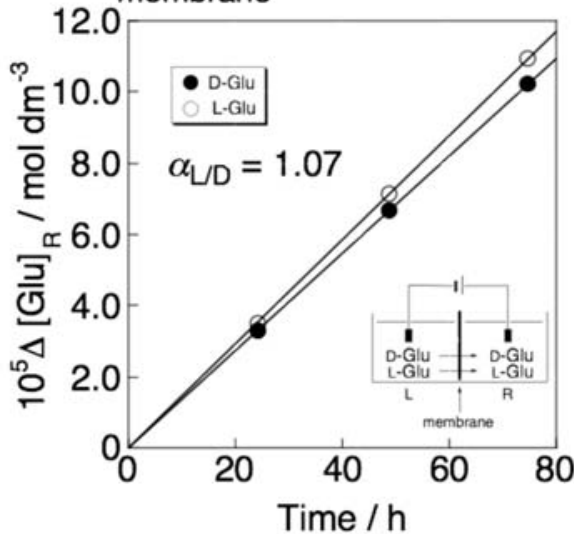

Figure 7: Time-transport curves of racemic mixture of Glu through Z-D-Glu molecularly imprinted (a) and Z-L-molecularly imprinted (b) membranes at $40^{\circ} \mathrm{C}$ in aqueous solution adopting a potential difference as a driving force for membrane transport. $(\Delta \mathrm{E}=6.0 \mathrm{~V})$.

(a) Z-D-GLu molecularly imprinted

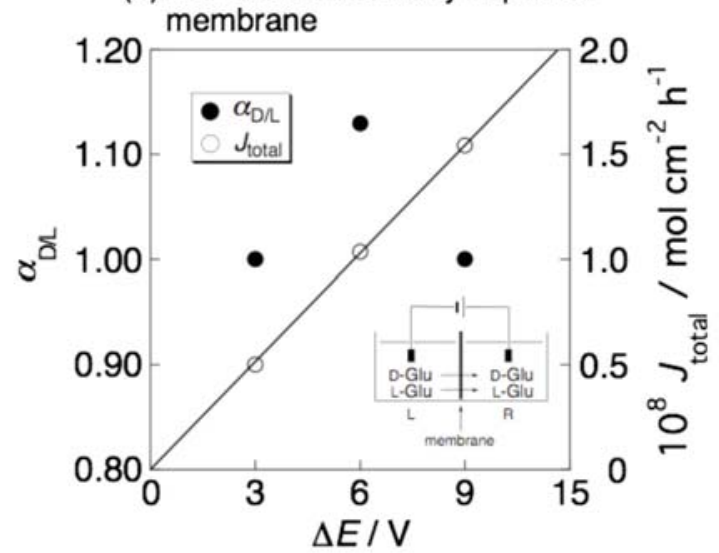

(b) Z-L-GLu molecularly imprinted membrane

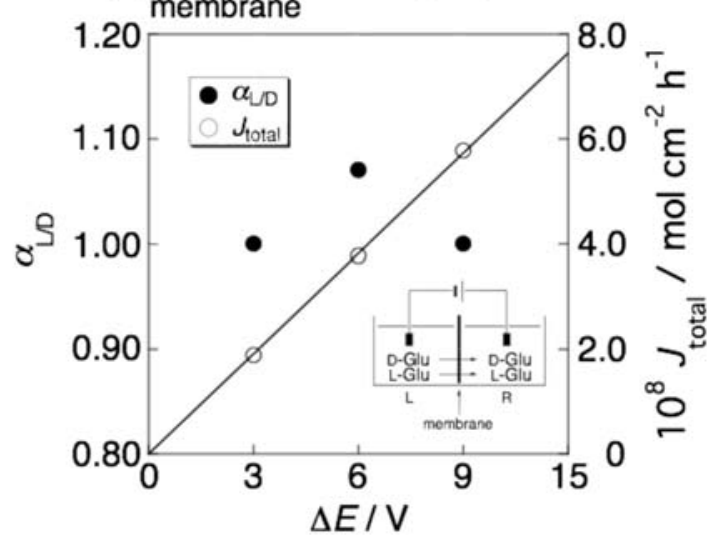

Figure 8: Effect of a potential difference on enantioselective electrodialysis of a racemic mixture of Glu through the Z-D-Glu molecularly imprinted membrane (a) and the Z-L-Glu molecularly imprinted one (b) at $40{ }^{\circ} \mathrm{C}$ in aqueous solution.

both membrane systems, the total flux increased with the increase in the potential difference, passing through origin. The permselectivities for both membranes were determined to be unity at the applied potential difference of $3.0 \mathrm{~V}$ and $9.0 \mathrm{~V}$. From previous results $[8,15,18]$, below the applied potential difference of 3.0 $\mathrm{V}$, opposite permselectivity would be observed.

\section{CONCLUSIONS}

Novel polyurea was synthesized from lysinyl residue, L-lysine-4-nitroanilide (L-Lys-4-NA) and 1,4phenylene diisocyanate (1,4-PDI). The optimum polyaddition condition was determined as follows; [LLys-4-NA] $=2.08 \times 10^{-1} \mathrm{~mol} \mathrm{dm}^{-3}$ and $[1,4-\mathrm{PDI}]=2.50 \mathrm{x}$ $10^{-1} \mathrm{~mol} \mathrm{dm}^{-3}$ ([L-Lys-4-NA $] /$ [1,4-PDI] $=0.83$. The polyurea thus prepared gave durable self-standing membranes and were converted into molecular recognition materials (membranes) adopting Z-D-Glu or
Z-L-Glu as a print molecule. The Z-D-Glu molecularly imprinted membrane adsorbed the D-isomer of Glu in preference to the corresponding L-Glu and vice versa. Even though the present polyurea consisted of L-lysinyl residue, both the $\mathrm{D}$-isomer and the L-isomer of print molecules worked as a print molecule to construct molecular recognition site in the membrane. Those two types of molecularly imprinted membrane showed chiral separation ability adopting a concentration gradient or applied potential difference as a driving force for membrane transport. The permselectivity was dependent on the magnitude of the driving force.

\section{REFERENCES}

[1] Maier NM, Franco P, Lindner W. Separation of enantiomers: needs, challenges, perspectives. J Chromato A 2001; 906: 333.

http://dx.doi.org/10.1016/S0021-9673(00)00532-X 
[2] Afonso CAM, Crespo JG. Recent Advances in Chiral Resolution through Membrane-Based Approaches. Angew Chem Int Ed 2004; 43: 5293-5. http://dx.doi.org/10.1002/anie.200460037

[3] Maier NM, Lindner W. Chiral recognition applications of molecularly imprinted polymers: a critical review. Anal Bioanal Chem 2007; 389: 377-97.

http://dx.doi.org/10.1007/s00216-007-1427-4

[4] Xie R, Chu L-Y, Deng J-G. Membranes and membrane processes for chiral resolution. Chem Soc Rev; 2008; 37: 1243-63.

http://dx.doi.org/10.1039/b713350b

[5] Higuchi A, Tamai. M, Ko, Y-A, Tagawa Y, Wu Y-H, Freeman BD, Bing J-T, Chang Y, Ling Q-D. Polymeric Membranes for Chiral Separation of Pharmaceuticals and Chemicals. Polym Rev 2010; 50: 113-43.

http://dx.doi.org/10.1080/15583721003698853

[6] Yoshikawa M, Izumi J, Kitao T, Sakamoto S. Molecularly Imprinted Polymeric Membranes Containing DIDE Derivatives for Optical Resolution of Amino Acids. Macromolecules 1996; 29: 8197-203.

http://dx.doi.org/10.1021/ma951716v

[7] Kondo Y, Yoshikawa M, Okushita H. Molecularly imprinted polyamide membranes for chital recognition. Polym Bull 2000; 44 517-24

[8] Yoshikawa M, Izumi J. Chiral Recognition Sites Converted from Tetrapeptide Derivatives Adopting Racemates as Print Molecules. Macromol Biosci 2003; 3: 487-98. http://dx.doi.org/10.1002/mabi.200350016

[9] Yoshikawa M, Nakai K, Matsumoto H, Tanioka, Guiver MD, Robertson GP. Molecularly Imprinted Nanofiber Membranes from Carboxylated Polysulfone by Electrospray Deposition. Macromol Rapid Commun 2007; 28: 2100-5.

http://dx.doi.org/10.1002/marc.200700359

[10] Sueyoshi Y, Fukushima C, Yoshikawa M. Molecularly imprinted nanofiber membranes from cellulose acetate aimed for chiral separation. J Membr Sci 2010; 357: 90-7. http://dx.doi.org/10.1016/j.memsci.2010.04.005

[11] Yoshikawa M, Tanioka A, Matsumoto H. Molecularly imprinted nanofiber membranes. Curr Opin Chem Eng 2011; 1: 18-26.

[12] Sueyoshi Y, Utsunomiya A, Yoshikawa M, Robertson GP, Guiver MD. Chiral separation with molecularly imprinted polysulfone-aldehyde derivatized nanofiber membranes. J Membr Sci 2012; 401-402: 89-96. http://dx.doi.org/10.1016/j.memsci.2012.01.033

[13] Ikeuchi Y, Nakagawa M, Yoshikawa M, Yoshida H, Sakurai $\mathrm{S}$. Chiral polyamides consisting of $\mathrm{N}$ - $\alpha$-benzoyl-L-glutamic acid as a diacid component. J Polym Sci: Part A: Polym Chem 2009; 47: 2530-8.

http://dx.doi.org/10.1002/pola.23335

[14] Nakagawa M, Ikeuchi Y, Yoshikawa M, Yoshida H, Sakurai $\mathrm{S}$. Optical resolution of racemic amino acid derivatives with chiral polyamides bearing glutamyl residue as a diacid component. J Appl Polym Sci 2012; 123: 857-65.

http://dx.doi.org/10.1002/app.34524

[15] Mizushima H, Yoshikawa M, Robertson GP, Guiver MD. Optical Resolution Membranes from Polysulfones Bearing Alanine Derivatives as Chiral Selectors. Macromol Mater Eng 2011; 296: 562-67.

http://dx.doi.org/10.1002/mame.201000396

[16] Mizushima H, Yoshikawa M, Li NW, Robertson GP, Guiver MD. Electrospun nanofiber membranes from polysulfones with chiral selector aimed for optical resolution. Eur Polym J 2012; 48: 1717-25.

http://dx.doi.org/10.1016/j.eurpolymj.2012.07.003

[17] Isezaki J, Yoshikawa M, Li NW, Robertson GP, Guiver MD. Polysulfones with Phenylalanine Derivatives as Chiral
Selectors - Membranes for Chiral Separation. J Membr Sep Technol 2012; 1: 1-8.

http://dx.doi.org/10.6000/1929-6037.2012.01.01.1

[18] Hatanaka M, Nishioka Y, Yoshikawa M. Polyurea With LLysinyl Residues as Components: Application to Membrane Separation of Enantiomers. Macromol Chem Phys 2011; 212: $1351-9$.

http://dx.doi.org/10.1002/macp.201100054

[19] Hatanaka M, Nishioka Y, Yoshikawa M. Polyurea Bearing LLysinyl Residue as a Chiral Building Block and Its Application to Optical Resolution. J Mater Sci Res 2012; 1 (4): 114-22. http://dx.doi.org/10.5539/jmsr.v1n4p114

[20] Hatanaka M, Nishioka Y, Yoshikawa M. Chiral separation with polyurea membrane consisting of L-lysinyl residue: Proposal of facile method for prediction of permselectivity. $\mathrm{J}$ Appl Polym Sci 2013; 128: 123-31. http://dx.doi.org/10.1002/app.38141

[21] Yeganeh H, Tamami B, Ghazi I. A novel direct method for preparation of aromatic polyimides via microwave-assisted polycondensation of aromatic dianhydrides and diisocyanates. Eur Polym J 2004; 40: 2059-64.

http://dx.doi.org/10.1016/j.eurpolymj.2004.05.022

[22] Riddick JA, Bunger WB, Sakano TL. Organic solvents. 4th edition, New York: Wiley; 1986.

[23] Silverstein RM, Webster FX. Spectrometric Identification of Organic Compounds. 6th ed. New York: Wiley; 1998.

[24] Stevens MP. Polymer Chemistry. 2nd ed. New York: Wiley; 1990.

[25] Feldman D, Barbalata A. Synthetic polymers. London: Chapman \& Hall; 1996.

[26] Walton DJ, Lorimer JP. Polymer. Oxford] Oxford University Press; 2000.

[27] Piletsky SA, Panasyuk TL, Piletskaya EV, Nicbolls LA, Ulbricht M. Receptor and transport properties of imprinted polymer membranes - a review. J Membr Sci 1999; 157: 263-78.

http://dx.doi.org/10.1016/S0376-7388(99)00007-1

[28] Haupt K, Mosbach K. Molecularly Imprinted Polymers and Their Use in Biomimetic Sensors. Chem Rev 2000; 100: 2495-504.

http://dx.doi.org/10.1021/cr990099w

[29] Sellergren B, Ed., Moleculraly imprinted polymers, Manmade mimics of antibodies and their applications in analytical chemistry. Amsterdam; Elsevier: 2001.

[30] Wulff G. Enzyme-like Catalysis by Molecularly Imprinted Polymers. Chem Rev 2002; 102: 1-28. http://dx.doi.org/10.1021/cr980039a

[31] Ulbricht M. Membrane separations using molecularly imprinted polymers. J Chromato B 2004; 804: 113-25. http://dx.doi.org/10.1016/j.jchromb.2004.02.007

[32] Alexander C, Andersson HS, Andersson LI, Ansell RJ, Kirsch $\mathrm{N}$, Nicholls IA, Whitcombe MJ. Molecular imprinting science and technology: a survey of the literature for the years up to and including 2003. J Mol Recog 2006; 19: 106-80.

http://dx.doi.org/10.1002/jmr.760

[33] Yoshikawa M. Molecularly imprinted polymeric membranes. Bioseparation 2001; 10: 277-86.

[34] Yoshikawa M, Izumi J, Ooi T, Kitao T, Guiver MD, Robertson GP. Carboxylated polysulfone membranes having a chiral recognition site induced by an alternative molecular imprinting technique. Polym Bull 1998; 40: 517-24. http://link.springer.com/content/pdf/10.1007\%2Fs002890050 285

[35] Kakuchi T, Takaoka Yokota T. Polymeric Chiral Crown Ethers VI. Optical Resolution of $\alpha$-Amino Acid by Polymers Incorporating 1,3;4,6-Di-O-benzylidene-D-mannitol Residues. Polym J 1990; 22: 199-205. http://dx.doi.org/10.1295/polymj.22.199 
[36] Masawaki T, Sasai M, Tone S. Optical Resolution of an Amino Acid by an Enantio Selective Ultrafiltration Membrane. J Chem Eng Jpn 1992; 25: 33-39. http://dx.doi.org/10.1252/jcej.25.33

[37] Aoki T, Tomizawa S, Oikawa E. Enantioselective permeation through poly\{y-[3(pentamethyldisiloxyanyl)propyl]-Lglutamate\} membranes. J Membr Sci 1995; 99: 117-25.
[38] Tone S, Masawaki T, Eguchi K. The optical resolution of amino acids by plasma polymerized terpene membranes. $\mathrm{J}$ Membr Sci 1996; 118: 31-40.

http://dx.doi.org/10.1016/0376-7388(96)00071-3

(C) 2013 Hatanaka et al.; Licensee Lifescience Global.

This is an open access article licensed under the terms of the Creative Commons Attribution Non-Commercial License (http://creativecommons.org/licenses/by-nc/3.0/) which permits unrestricted, non-commercial use, distribution and reproduction in any medium, provided the work is properly cited. 